\title{
Article \\ Prediction of Peak Particle Velocity Caused by Blasting through the Combinations of Boosted-CHAID and SVM Models with Various Kernels
}

\author{
Jie Zeng ${ }^{1}$, Panayiotis C. Roussis ${ }^{2}$, Ahmed Salih Mohammed ${ }^{3} \mathbb{D}$, Chrysanthos Maraveas ${ }^{4}(\mathbb{D}$, \\ Seyed Alireza Fatemi ${ }^{5}$, Danial Jahed Armaghani ${ }^{6}(\mathbb{D})$ and Panagiotis G. Asteris ${ }^{7 *} \mathbb{D}$
}

check for

updates

Citation: Zeng, J.; Roussis, P.C.; Mohammed, A.S.; Maraveas, C.; Fatemi, S.A.; Armaghani, D.J.; Asteris, P.G. Prediction of Peak Particle Velocity Caused by Blasting through the Combinations of Boosted-CHAID and SVM Models with Various Kernels. Appl. Sci. 2021, 11, 3705. https://doi.org/10.3390/app11083705

Academic Editor: Aki Mikkola

Received: 8 March 2021

Accepted: 17 April 2021

Published: 20 April 2021

Publisher's Note: MDPI stays neutral with regard to jurisdictional claims in published maps and institutional affiliations.

Copyright: (c) 2021 by the authors. Licensee MDPI, Basel, Switzerland. This article is an open access article distributed under the terms and conditions of the Creative Commons Attribution (CC BY) license (https:// creativecommons.org/licenses/by/ $4.0 /)$.
1 Department of Transportation and Municipal Engineering, Chongqing Jianzhu College, Chongqing 400072, China; ponia001@cqjzc.edu.cn

2 Department of Civil and Environmental Engineering, University of Cyprus, Nicosia 1678, Cyprus; roussis@ucy.ac.cy

3 Civil Engineering Department, College of Engineering, University of Sulaimani, Kurdistan Region, Sulaymaniyah 46001, Iraq; ahmed.mohammed@univsul.edu.iq

4 Department of Civil Engineering, University of Patras, 26504 Patras, Greece; c.maraveas@maraveas.gr

5 Department of Civil and Environmental Engineering, Amirkabir University of Technology, Tehran 15875-4413, Iran; a.fatemi@aut.ac.ir

6 Department of Civil Engineering, Faculty of Engineering, University of Malaya, Kuala Lumpur 50603, Malaysia; danialarmaghani@um.edu.my

7 Computational Mechanics Laboratory, School of Pedagogical and Technological Education, 14121 Heraklion Athens, Greece

* Correspondence: panagiotisasteris@gmail.com

\begin{abstract}
This research examines the feasibility of hybridizing boosted Chi-Squared Automatic Interaction Detection (CHAID) with different kernels of support vector machine (SVM) techniques for the prediction of the peak particle velocity (PPV) induced by quarry blasting. To achieve this objective, a boosting-CHAID technique was applied to a big experimental database comprising six input variables. The technique identified four input parameters (distance from blast-face, stemming length, powder factor, and maximum charge per delay) as the most significant parameters affecting the prediction accuracy and utilized them to propose the SVM models with various kernels. The kernel types used in this study include radial basis function, polynomial, sigmoid, and linear. Several criteria, including mean absolute error (MAE), correlation coefficient (R), and gains, were calculated to evaluate the developed models' accuracy and applicability. In addition, a simple ranking system was used to evaluate the models' performance systematically. The performance of the R and MAE index of the radial basis function kernel of SVM in training and testing phases, respectively, confirm the high capability of this SVM kernel in predicting PPV values. This study successfully demonstrates that a combination of boosting-CHAID and SVM models can identify and predict with a high level of accuracy the most effective parameters affecting PPV values.
\end{abstract}

Keywords: ground vibration; blasting operation; boosting-CHAID: support vector machine; input selection

\section{Introduction}

Blasting is a usual method of breakage in mining and quarrying processes. It is also one of the standard techniques used in several projects such as road and tunnel construction [1]. In excavation processes, blasting is formed from boring some series of explosion-holes nearly equidistant to the bench's free face [2]. Certain actions generate some undesirable environmental effects, for example, air overpressure, ground vibrations, flyrock, and backbreak around the blasting area [3-14]. Despite the availability of several experimental analytic solutions for predicting these environmental effects, these specifications take into account only a small number of important factors, whereas other influential parameters such as the blasting pattern and geological circumstances influence these impacts as 
well $[15,16]$. Therefore, experimental methods are not precise enough, while in some cases, predicting the environmental effect with greater certainty is crucial for reducing ecological harm due to blasting [17].

Numerous studies have attempted to investigate ground vibrations $[18,19]$. They determined ground vibration as a surging movement that distributes from the explosion unto close fields. The ground vibrations include two main components, i.e., frequency and peak particle velocity (PPV). Indian Standards [20] consider PPV as a vibration index, which is a substantial indication for gauging the physical harm principle. The destruction of the neighboring arrangements, the groundwater, and damages of nearby area's ecology are typically caused by significant ground vibration level $[15,21,22]$. The most significant factors for ground vibration resulting from blasting are blast design, the amount of space from the blast-face, geological circumstances, properties of the rock mass, and explosive charge weight per delay $[23,24]$.

Some researchers ascertained different experimental indicators for the prediction of PPV [20,25-27]. Nevertheless, during a specific explosion, forecasted PPVs acquired by these independent variables are not the same, and no similarity is available in their outcomes. Moreover, Armaghani et al. [1] demonstrated that these experimental predictors merely study two important factors including charge per delay and distance from blast-face whereas other useful factors, for example, blast geometry and geological circumstances influence on PPV as well.

Many researchers have extensively utilized soft computing (SC) methods to solve engineering and science problems as well as PPV resulting from blasting [28-68]. Singh and Singh [69] used artificial neural network (ANN) and regression analysis to determine the PPV. They showed that ANN outperforms regression analysis for PPV prediction. In Turkey, Fişne et al. [70] used fuzzy logic method and regression analysis for PPV prediction using 33 data acquired from Akdaglar mine. They assumed that the charge weight and distance from the blast-face are independent variables. These authors found that the fuzzy model outperformed the statistical methods. In Iran, Monjezi et al. [11] estimated PPVs utilizing various experimental formulas and ANN method. The authors acquired data from the Shur River Dam. Their ultimate findings indicated the superiority of the ANN model over the experimental expressions. Again in Iran, Saadat et al. [71] employed ANN models for PPV prediction. They collected 69 data from Gol-E-Gohar iron mine. The authors compared their results with those of typical experimental and statistical methods. As expected, the results showed that ANN outperformed other models. In Malaysia, Armaghani et al. [1], Hajihassani et al. [17], and Shirani Faradonbeh et al. [72] used particle swarm optimization (PSO)-ANN, imperialism competitive algorithm (ICA)-ANN and gene expression programming (GEP) techniques, respectively, to estimate ground vibrations resulting from blasting. In Vietnam, Nguyen et al. [73,74] respectively developed two new models namely the K-means clustering (HKM)-Cubist algorithm (CA), and the support vector regression (SVR)-genetic algorithm (GA) for PPV prediction.

In the present study, we compiled the most influential studies for the prediction of PPV using soft computing and artificial intelligent techniques (Table 1). While a considerable number of studies used Adaptive Neuro-Fuzzy Inference System (ANFIS) and ANN to predict the PPV, a limited number of studies used Support Vector Machine (SVM) to predict the PPV. Among the researchers that utilized the SVM to examine the PPV, no study assessed the applicability of different kernels of SVM for the PPV prediction. In addition, a very limited number of studies employed the decision trees to forecast the PPV, which also has been noted by other researchers [75]. The decision trees that were used by these studies were mostly Classification and Regression Tree (CART), Random Forest (RF), and ChiSquared Automatic Interaction Detection (CHAID). No study utilized the decision trees for input selection while the suitability of these techniques especially those including ensemble and boosting features are acknowledged in the literature [30]. Therefore, this study uses a boosted-CHAID technique for input selection and uses the results of this approach to develop the SVM models with various kernels for PPV prediction. Then, the best SVM 
kernel will be selected and introduced to predict the PPV induced by mine blasting. The paper explains the research as follows. In the next section, the modelling methodology and case study are presented. The methodology section is followed by research results and their evaluations. This paper closes with a discussion and conclusion of the findings of this research.

Table 1. The most prominent research on the PPV prediction by means of the SC procedures.

\begin{tabular}{cccc}
\hline Study & Model & Model Input Number & Site Location \\
\hline Singh and Singh [69] & ANN & 9 & India \\
Iphar et al. [76] & ANFIS & 2 & Turkey \\
Khandelwal and Singh [18] & ANN & 10 & India \\
Monjezi et al. [19] & ANN & 4 & Iran \\
Mohamed [77] & ANN, FIS & 2 & Egypt \\
Khandelwal et al. [78] & ANN & 2 & India \\
Fişne et al. [70] & FIS & 2 & Turkey \\
Mohamadnejad et al. [79] & SVM, ANN & 2 & Iran \\
Mohammad et al. [80] & ANN & 9 & Malaysia \\
Monjezi et al. [11] & ANN & 3 & Iran \\
Ghasemi et al. [81] & FIS & 6 & Iran \\
Armaghani et al. [1] & PSO-ANN & 10 & Malaysia \\
Hajihassani et al. [17] & ICA-ANN & 7 & Malaysia \\
Dindarloo [82] & SVM & 12 & Iran \\
Hajihassani et al. [2] & PSO-ANN & 8 & Malaysia \\
Hasanipanah et al. [83] & SVM & 2 & Iran \\
Armaghani et al. [84] & ANFIS & 2 & Malaysia \\
Ghoraba et al. [85] & ANN, ANFIS & 2 & Iran \\
Shirani Faradonbeh et al. [72] & GEP & 6 & Malaysia \\
Hasanipanah et al. [86] & CART & 2 & Iran \\
Shahnazar et al. [87] & PSO-ANFIS & 2 & Malaysia \\
Armaghani et al. [88] & ICA & 2 & Malaysia \\
Nguyen et al. [73] & HKM-CA & 4 & Vietnam \\
Nguyen et al. [74] & SVR-GA & 4 & Vietnam \\
Zhang et al. [75] & RF, CART, CHAID & 6 & Malaysia \\
Zhou et al. [16] & RF, BN & 5 & Malaysia \\
Huang et al. [5] & FA-ANN & 4 & Malaysia \\
\hline
\end{tabular}

FIS: fuzzy inference system, CART: Classification and regression tree, FA: firefly algorithm, BN: Bayesian network.

\section{Materials and Methods}

In this study, a systematic approach was employed to combine the boosting-CHAID as an input selection technique, with SVM models with diverse kernels to predict the PPV resulting from blasting. Initially, a boosting-CHAID model was developed and the most important variables for predicting the PPV were identified. Subsequently, the SVM models with various kernels (sigmoid, SIG; polynomial, POL; linear, LIN; and radial basis function, RBF were built using the aforementioned variables. Finally, the models' results were evaluated by applying certain performance criteria. Figure 1 presents the flowchart of the approach employed in this study. It is important to note that three methods of model evaluation, including performance indices, variable importance, and ranking system, were used in this study.

\subsection{Input Selection Technique}

The Chi-Squared Automatic Interaction Detection (CHAID) algorithm creates decision trees employing ChiSquare statistics to establish the optimal divisions [89]. CHAID generates non-binary trees. Some divisions may possess more than two branches that are especially suitable for the examination of complex datasets. CHAID converts continuous inputs into ordinal type employing binning techniques since it handles merely categorical inputs. During the learning process, a heuristic statistical technique is employed to examine the relationship between a set of categorical inputs and the target variable. It offers a tree diagram that shows the kinds of inputs that most significantly affect the value of the target variable. CHAID modelling steps are (1) binning, (2) merging, (3) splitting, and (4) stopping. 


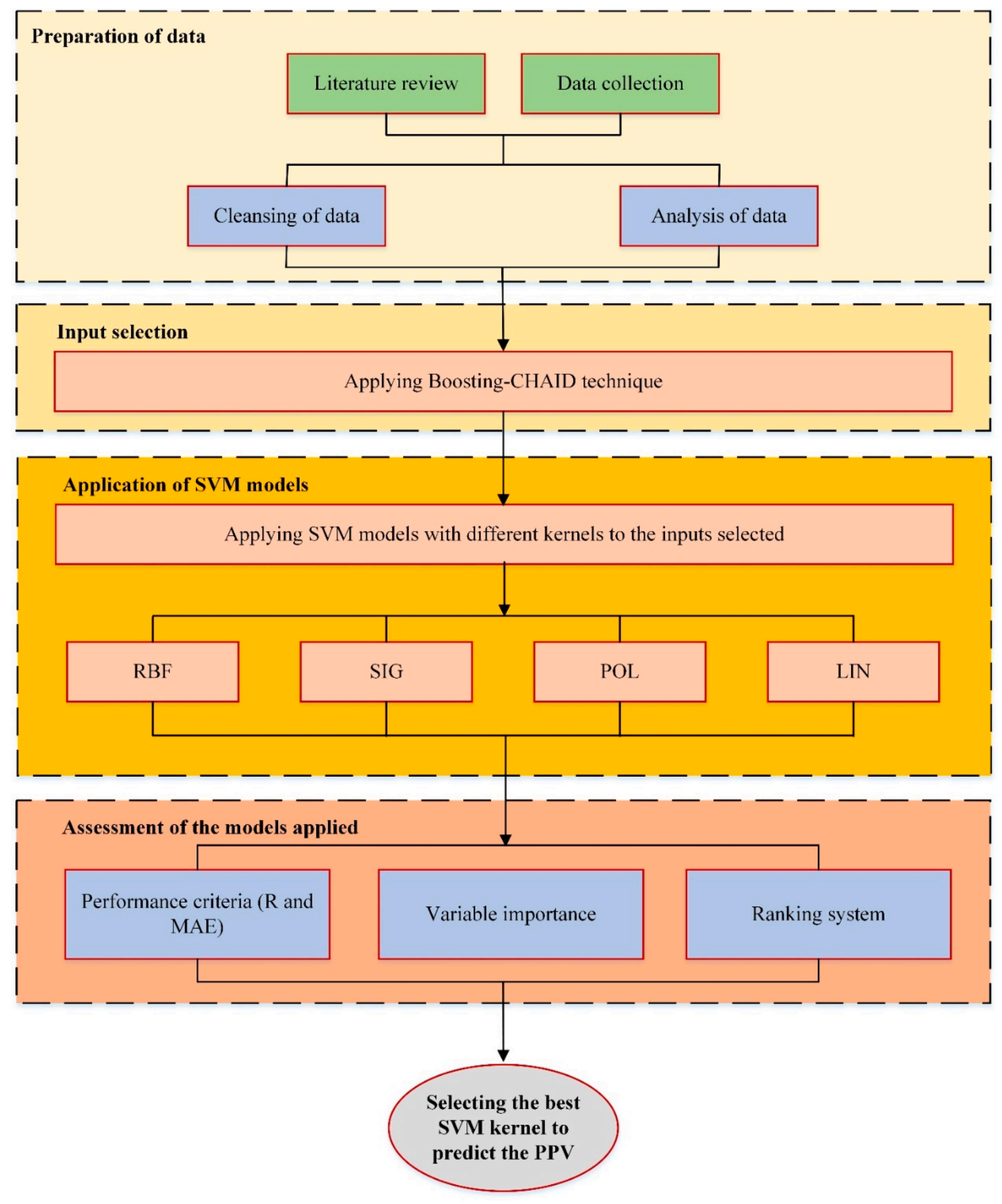

Figure 1. A systematic flowchart of this study.

Boosting procedures were introduced by Freund and Schapire [90], who utilized resampling and merging algorithms to develop the weights of misclassified examples. In this study, we utilized boosted-CHAID technique for input selection since a single tree may not show the importance of ranking variables, and they could be completely masked by other related inputs. 


\subsection{SVM Model and Its Variants}

One of the most prominent supervised machine learning (ML) techniques that apply statistical learning principles and the necessary risk minimization system is the SVM [91]. This technique revises the non-linear system into a linear format by creating a hyperplane and converting the aforementioned system into a simplistic and processable setup [92] as shown in Figure 2. The data transmutation is conducted utilizing an analytical and precise function recognized as the Kernel function. The SVM intends to obtain the best margin of division between the groups and creates a classification hyperplane within the middle of the most significant margin [93]. These couple classes are named as " +1 " (positive samples), which indicates the circumstance over the hyperplane, and " -1 " (negative samples) describes the circumstance under the hyperplane. The characteristics of new data afterward can forecast the assortment to which a new record should fit.

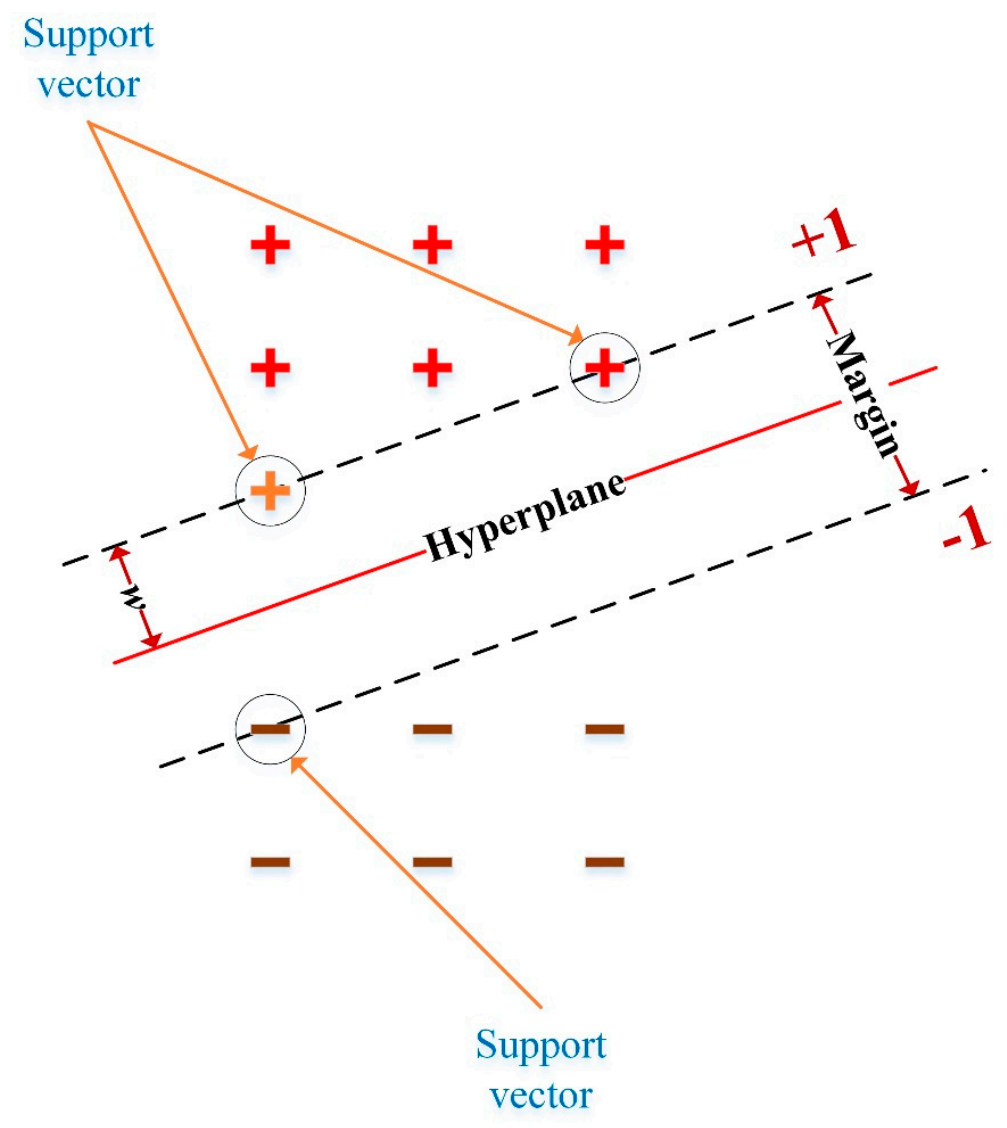

Figure 2. Representation of SVM.

The abovementioned step is executed for both classification and regression. With regards to classification, the aforementioned minimization is made assuming that all samples are entirely classified, while the regression analysis follows the provision that the " $y$ " value of each example varies less than the demanded precision of $\epsilon$ from $f(x)$. For classification, the main aim is to find a function $f(x)=w x+b$ where $f(x) \geq 1$ for positive examples and $f(x) \leq-1$ for negative examples. Under these conditions, we want to maximize the margin which is nothing more than minimizing the derivative of $f^{\prime}=w$. For regression, the objective is to determine a function $f(x)=w x+b$ (pale diagonal line) following the condition that $f(x)$ is within a required accuracy $\epsilon$ from the value $y(x)$ (vertical bars) of every data point, namely $|y(x)-f(x)| \leq \epsilon$ where epsilon is the distance between the dashed and the pale diagonal line (Figure 3). 


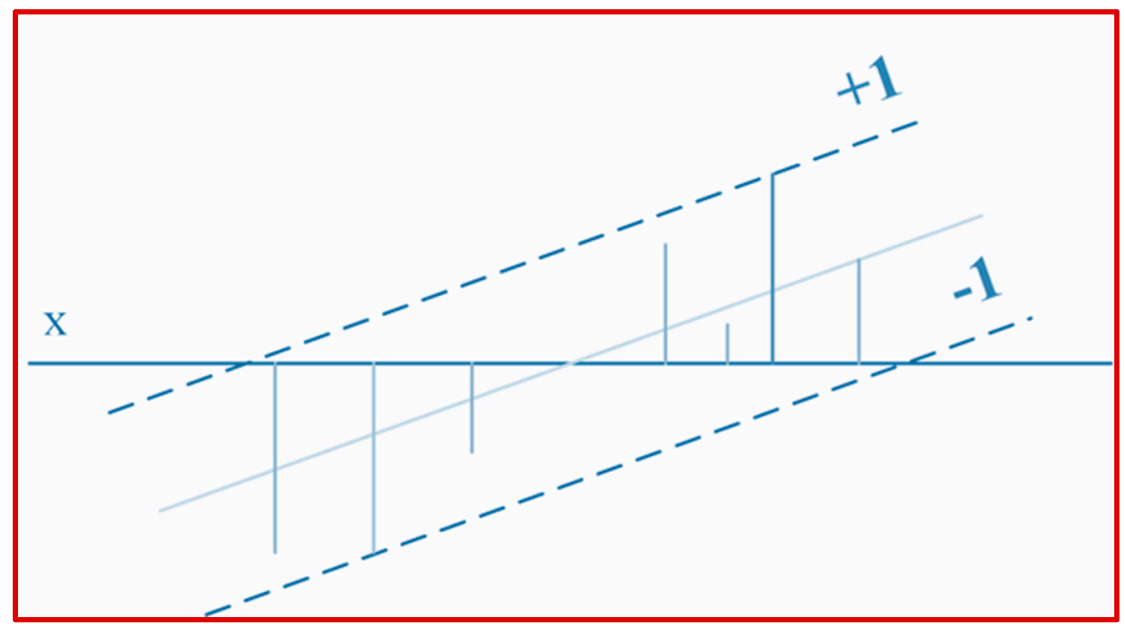

Figure 3. SVM arrangement for regression.

This research examined the SVM model with diverse kernels, including RBF, LIN, SIG, and POL to predict the PPV caused by quarry blasting. Typically, "Kernel" refers to implementing a linear classifier to resolve a non-linear problem. In ML technique, this Kernel is also called "Kernel trick". LIN Kernel is suitable for simple and linearly separated data. Otherwise, other functions should be employed. It is worth mentioning that the SIG are identical to the RBF for some parameters of SVM [94]. The kernel of LIN is the particular form of the RBF and in circumstances that RBF is adopted during processing, it is unnecessary to apply the kernel of LIN. With regards to precision, the RBF has a greater ability to interpolate compared to the SIG. This triggers RBF to produce additional consistent outcomes. Instead, the RBF is not able to create longer-range extrapolation. The SIG may have a great inconsistency since it is not severely positive certain which may cause incorrect calculation. In a study by Tehrany et al. [95], it was asserted that the POL is able to produce better extrapolations. Figure 4 presents the kernels' formulas. This study utilized every type of kernels to investigate the efficiency of each kernel to predict the PPV induced by blasting. Figure 4 shows that there are some critical coefficients like " $\gamma$ " and " $d$ " for different kernels such as RBF and POL that need to be designed. In Figure 4, " $\gamma$ " is the kernel width and " $d$ " is degree of polynomial kernel. It is vital to discover the correct value of " $\gamma$ " and " $d$ " because " $\gamma$ " regulates the level of nonlinearity of the SVM model and " $d$ " determines the level of the polynomial kernel.

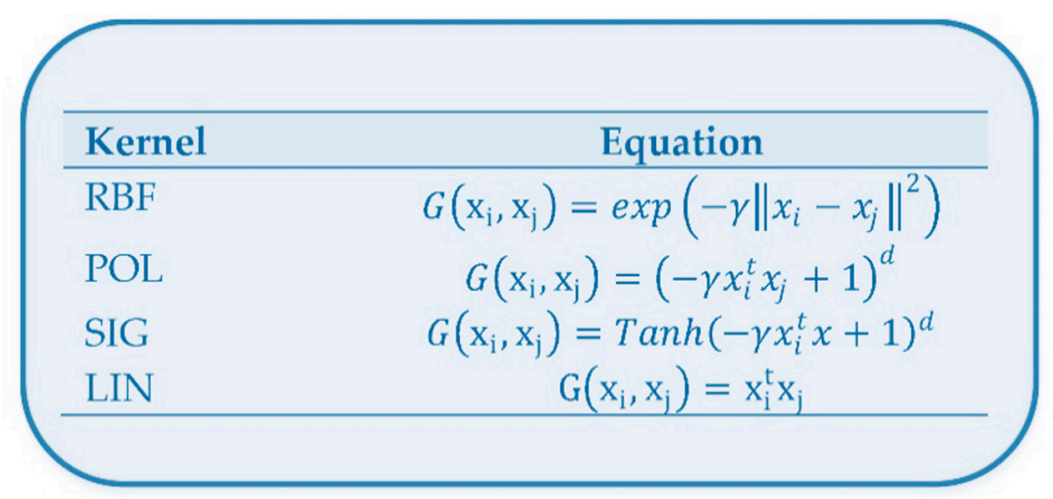

Figure 4. Kernels' formula.

\subsection{Experimental Database}

While in the process of developing a forecast model, much attention has been devoted to the computational model itself, only marginal attention has been paid by researchers to the actual database used for the development, training, and validation of the model. 
Without underestimating the high importance and added value of research efforts towards the development of new computational models, we strongly believe that the reliability of the database is of utmost importance in achieving the ultimate goal of a reliable forecast. In fact, in addition to reliable data, a reliable database must comprise a sufficient amount of data, covering the full range of parameter (input and output) values that influence the problem under investigation.

It should be noted that the term "sufficient amount of data" does not necessarily imply a high amount of data, but rather datasets that cover a wide range of combinations of input parameter values, thus assisting in the model capability to simulate the problem. The demand for a reliable and capable database is especially crucial in the case of experimental databases, that is databases which are compiled using experimental results. In this case, high deviation between experimental values is frequently noticed, not only between experiments conducted by different research teams and laboratories, but even between datasets that derive from experiments conducted on specimens of the same synthesis, produced by the same technicians, cured under the same conditions and tested implementing the same standards and the same testing instruments.

In light of the above discussion, a big experimental database consisting of 166 datasets was composed. To provide a significant amount of data for the calculation of the environmental effects of mine blasting, we studied four quarries in Malaysia. Details for these sites are presented in Figure 5. The goal of mine explosion is to provide aggregate material for various applications. Depending on the weather, six to twelve mine explosions are performed each month.

\begin{tabular}{|lllll|}
\hline Quarry name & $\begin{array}{l}\text { Distance to } \\
\text { Johor (km) }\end{array}$ & Latitude & Longitude & $\begin{array}{l}\text { Bench } \\
\text { height (m) }\end{array}$ \\
\hline Taman Bestari & 17 & $1^{\circ} 60^{\prime} 41^{\prime \prime} \mathrm{N}$ & $103^{\circ} 78^{\prime} 32^{\prime \prime} \mathrm{E}$ & $7-17$ \\
Senai Jaya & 27 & $1^{\circ} 36^{\prime} 00^{\prime \prime} \mathrm{N}$ & $103^{\circ} 39^{\prime} 00^{\prime \prime} \mathrm{E}$ & $13-24$ \\
Kulai & 35 & $1^{\circ} 39^{\prime} 21^{\prime \prime} \mathrm{N}$ & $103^{\circ} 36^{\prime} 11^{\prime \prime} \mathrm{E}$ & $10-22$ \\
Bukit Indah & 18 & $1^{\circ} 93^{\prime} 12^{\prime \prime} \mathrm{N}$ & $103^{\circ} 35^{\prime} 08^{\prime \prime} \mathrm{E}$ & $15-28$ \\
\hline
\end{tabular}

Figure 5. Location information of the quarry sites.

Among these 166 data samples and investigated blasting events, 80 blasting events were investigated in Kulai quarry site. Then, 31, 29, and 26 blasting events were investigated in Bukit Indah, Senai Jaya, and Taman Bestari quarry sites, respectively. The lowest hole depth $(10 \mathrm{~m})$ was in the Kulai site, while the biggest hole depth $(28 \mathrm{~m})$ was in the Bukit Indah site. We compiled a database of 166 data samples from field measurements. The following parameters influencing the blast effect were recorded: powder factor $\left(\mathrm{kg} / \mathrm{m}^{3}\right)$, spacing $(\mathrm{m})$, stemming length $(\mathrm{m})$, burden $(\mathrm{m})$, the maximum charge per delay $(\mathrm{kg})$, and the blast-face distance to the monitoring point $(\mathrm{m})$. Actually, the mentioned parameters are considered as a common blasting data and have been utilized by many published works in literature $[1,17,19,22]$. It is also important to mention that the most important input factors in measuring/predicting the PPV are the maximum charge per delay and the distance from the blast-face $[21,22,96,97]$. In the established database, we used a $115 \mathrm{~mm}$ diameter for blast-holes. Fine gravel as a well-known stemming material was used in these operations. We recorded the PPV using a VibraZEB seismograph equipment at specific locations. Table 2 presents a summary of the measured input and output variables including unit, maximum, minimum, mean, and standard deviation. The frequency distributions of the PPV employed in this investigation are presented in Figure 6. 
Table 2. Summary of parameters in the projecting models.

\begin{tabular}{cccccc}
\hline Variable (Category) & Unit & Minimum & Maximum & Mean & Standard Deviation \\
\hline Burden to spacing (input) & - & 0.41 & 0.91 & 0.75 & 0.103 \\
Distance from the blast-face (input) & $\mathrm{m}$ & 65 & 710 & 329 & 142.961 \\
Maximum charge per delay (input) & $\mathrm{kg}$ & 69.79 & 309.09 & 202.44 & 64.534 \\
Powder factor (input) & $\mathrm{kg} / \mathrm{m}^{3}$ & 0.24 & 0.98 & 0.69 & 3.65 \\
Spacing (input) & $\mathrm{m}$ & 2.2 & 5.1 & 2.87 & 0.721 \\
Stemming length (input) & $\mathrm{m}$ & 1.4 & 4 & 14.4 & 0.619 \\
\hline PPV (target) & $\mathrm{mm} / \mathrm{s}$ & 1.21 & 37.44 & 8.673 \\
\hline
\end{tabular}

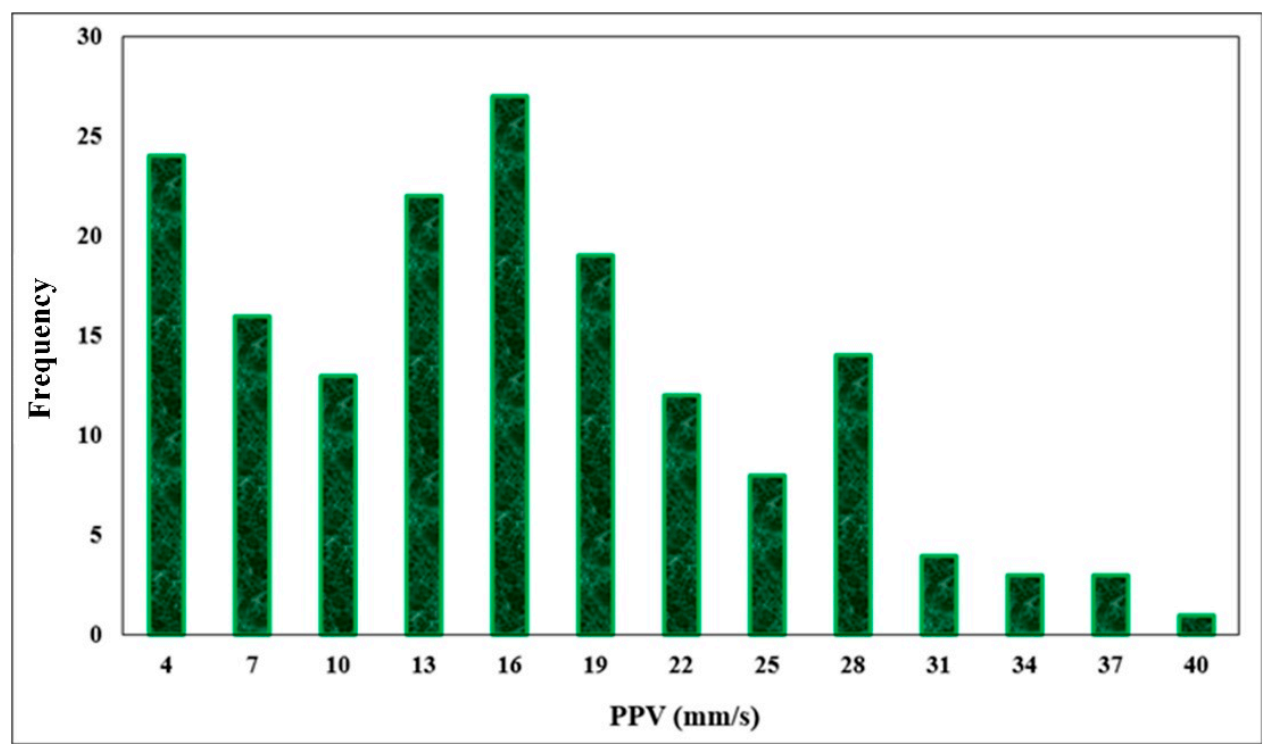

Figure 6. Measured PPV values and their frequency distribution.

\section{Models' Application}

\subsection{Input Selection}

We employed a hybrid approach for input selection. This technique was applied to six inputs for predicting the PPV values. The model was developed using the following parameters and settings: the tree growing algorithm was set to CHAID; the maximum tree depth was set as five; the minimum records in parent and child branches were assigned to two and one, respectively; the number of component models for boosting was selected as 10 , and significance level for splitting and merging was set as 0.05 . The accuracy of the CHAID and boosted CHAID models were $79.6 \%$ and $0.89 \%$, which showed the superiority of the boosted model over the single tree model. According to the boosted-CHAID model results, four inputs, including distance $(\mathrm{m})$, stemming $(\mathrm{m})$, powder factor $\left(\mathrm{kg} / \mathrm{m}^{3}\right)$, and maximum charge per delay $(\mathrm{kg})$, were the most important predictors/variables for the PPV forecast. Then, these critical inputs were used to apply the SVM models with diverse Kernels to predict the PPV caused by quarry blasting.

\subsection{SVM Models with Different Kernels}

This study applied four SVM models with four different Kernels, including RBF, polynomial, sigmoid, and linear. We used four parameters, including stemming, powder factor, the maximum charge per delay, and distance, which were identified as the most critical and relevant parameters for developing the SVM models. The research team used several considerations for developing these models. Stopping criteria were set as $1.0 \times 10^{-3}$; the regularization parameter $(C)$ was established as 10 ; and the regression precision (epsilon) was developed as 0.1 . Before the models' development, the data were split into train and test partitions using a ratio of 80:20. Thus, 104 samples were used in the 
training phase, and 36 samples were used for the testing phase. The measured PPV values and predicted values by all four models are shown in Figure 7.

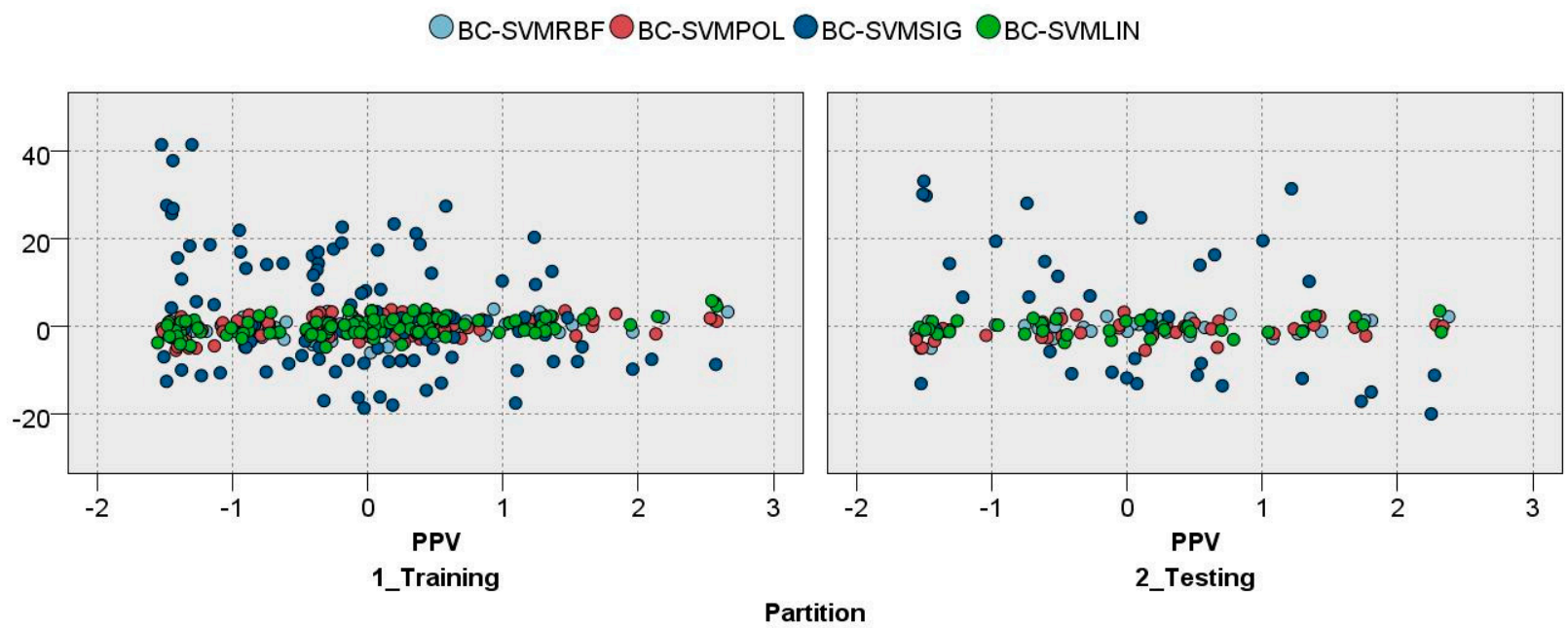

Figure 7. Predicted PPV values of the SVM models with different Kernels.

This research used two commonly used criteria for assessing the models' performance. These criteria included the Pearson's correlation coefficient $(R)$ and the mean absolute error $(M A E)$. In addition, a gain chart also was used to illustrate the performance of the models graphically:

$$
\begin{gathered}
R=\frac{\sqrt{\sum_{i=1}^{n}\left(y_{i m}-y_{i p}\right)^{2}}}{\sqrt{\sum_{i=1}^{n}\left(y_{i m}-\bar{y}_{i m}\right)^{2}}} \\
M A E=\frac{1}{N} \sum_{j=1}^{N}\left|y_{i m}-y_{i p}\right|
\end{gathered}
$$

where $y_{i m}, y_{i p}$, and $\bar{y}_{i m}$ indicate the measured, predicted and the mean of measured values, $n$ represents the total number of data.

A simplistic ranking system that rates the performance of the models for each partition was also developed. In this system, training and testing rankings were assigned to each model. Also, an accumulative ranking was produced, which was the total of the training and testing ranks. The formula for computing the accumulative ranking for each model is presented below:

$$
A-R=\sum\left(\alpha_{t r}+\beta_{t r}\right)+\left(\alpha_{t e}+\beta_{t e}\right)
$$

where, $A-R$ is the accumulative ranking of each model, $\alpha$ denotes the ranking of $R, \beta$ shows the ranking of MAE, " $t r$ " means the training ranking, and " $t e$ " signifies the testing ranking.

The performances of the models developed in this study are shown in Table 3. As can be seen, for the training phase, the BC-SVMRBF model achieved the highest ranks of $R$ and $M A E$ compared to other models. On the other hand, the lowest rankings of $R$ and $M A E$ belonged to the BC-SVMSIG model in the training phase. For the testing phase, the BC-SVMRBF model outperformed other models in terms of $\mathrm{R}$; however, regarding the $M A E$, the BC-SVMLIN achieved the highest ranking. Again, the BC-SVMSIG model achieved the lowest ranking in the testing phase comparing with other models. With regards to the accumulative ranking, the BC-SVMRBF model achieved the highest ranking $(A-R$ ranking $=15)$, followed by the BC-SVMLIN model $(A-R$ ranking $=12)$. Alternatively, BC-SVMSIG had the worst performance and consequently had the lowest accumulative ranking. 
Table 3. Performance results and ranking values of different ML approaches applied in this study.

\begin{tabular}{|c|c|c|c|c|c|c|c|c|c|c|c|}
\hline \multirow{3}{*}{ Model } & \multicolumn{4}{|c|}{ TRAIN } & \multicolumn{4}{|c|}{ TEST } & \multirow{3}{*}{$\begin{array}{c}\text { Train } \\
\text { Ranking }\end{array}$} & \multirow{3}{*}{$\begin{array}{c}\text { Test } \\
\text { Ranking }\end{array}$} & \multirow{3}{*}{$A-R$} \\
\hline & \multicolumn{2}{|c|}{$R$} & \multicolumn{2}{|c|}{ MAE } & \multicolumn{2}{|c|}{$R$} & \multicolumn{2}{|c|}{ MAE } & & & \\
\hline & V & $R$ & $\mathrm{~V}$ & $R$ & V & $R$ & $\mathrm{~V}$ & $R$ & & & \\
\hline BC-SVMRBF & 0.955 & 4 & 0.372 & 4 & 0.965 & 4 & 0.472 & 3 & 8 & 7 & 15 \\
\hline BC-SVMPOL & 0.946 & 3 & 0.388 & 2 & 0.935 & 2 & 0.488 & 2 & 5 & 4 & 9 \\
\hline BC-SVMSIG & -0.208 & 1 & 10.793 & 1 & -0.342 & 1 & 14.455 & 1 & 2 & 2 & 4 \\
\hline BC-SVMLIN & 0.944 & 2 & 0.387 & 3 & 0.959 & 3 & 0.471 & 4 & 5 & 7 & 12 \\
\hline
\end{tabular}

Value: V; Ranking: $R$; Accumulative ranking: $A-R$.

We also employed a gain chart to compare the models developed in this study. It is critical to note that the "gain" refers to the successfulness of a predictive technique to gauge the amounts higher than the middle point of the field's range (PPV > 0.557). Mathematically, the gain is calculated as follow:

$$
\text { Gain } \%=\frac{q}{w} \times 100
$$

where, " $q$ " refers to the quantity of hits in quantile and " $w$ " shows the whole quantity of hits.

In the diagram resulted from the gain calculation, the faultless model with tremendous confidence is denoted by the blue line, the diagonal red line denotes the accidental model, and the other lines in the middle denote the models utilized in this research. Generally speaking, the higher-level lines indicate higher prediction accuracy models, especially on the chart's left side. The domain within a red line model illustrates the gain difference between an applied and an accidental model. The domain mentioned above illustrates the superiority of an implemented versus accidental model. The range between an applied and the best model indicates areas of improvement for the applied model. The results of the gain's computation are presented in Figure 8. The results showed that BC-SVMSIG (the green line) had the worst gain for both the training and testing phases.

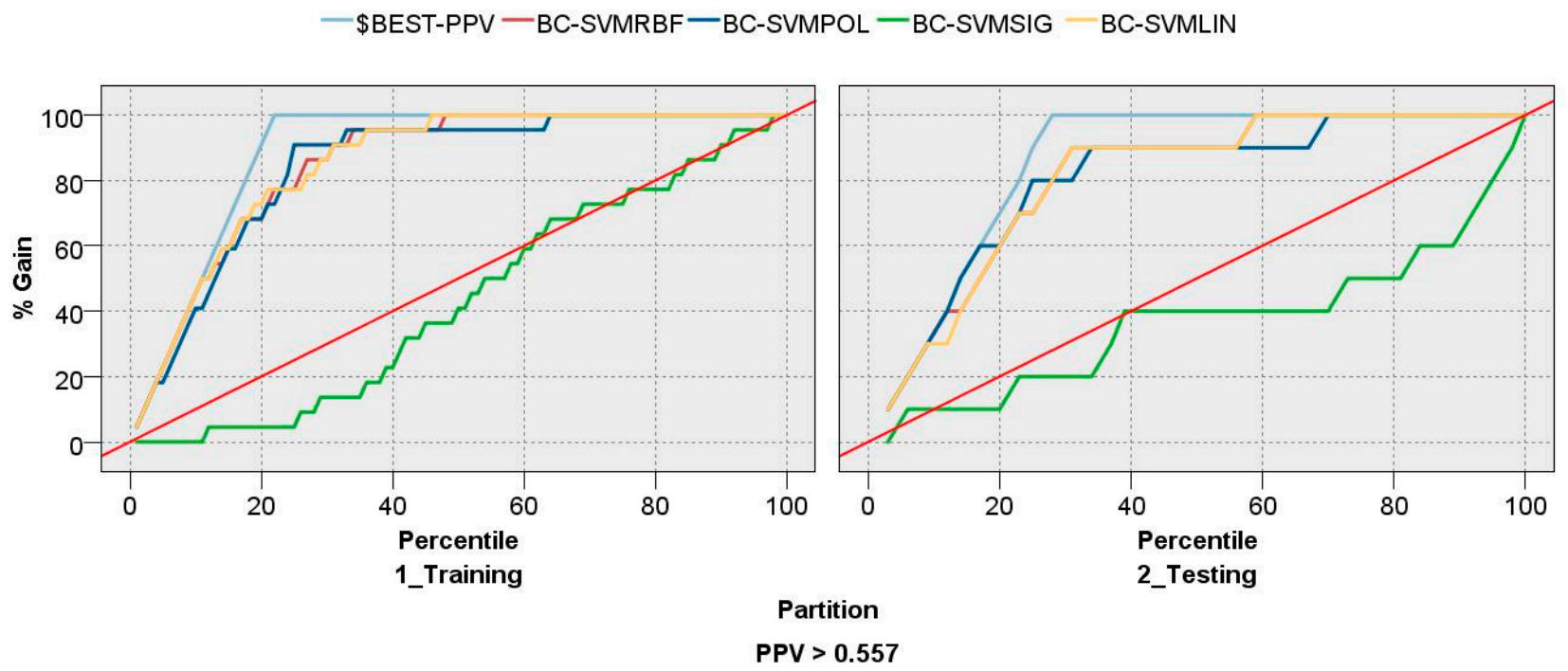

Figure 8. Gain chart of the proposed models.

The prominence of the input variables of different SVM models was identified and shown in Figure 9. As can be seen, all models except BC-SVMSIG identified distance as the most important predictor for the PPV prediction. Besides, BC-SVMRBF and BC-SVMLIN models similarly acknowledged "distance" as the most influential factor on the PPV. The "stemming" was recognized as an influential predictor only by BC-SVMPOL and BC- 
SVMSIG models. While the former model identified the "stemming" as another significant variable, the latter identified the "stemming" as the most significant PPV predictor. The "maximum charge per delay" and "powder factor" were selected as an influential factor only by the BC-SVMSIG model.

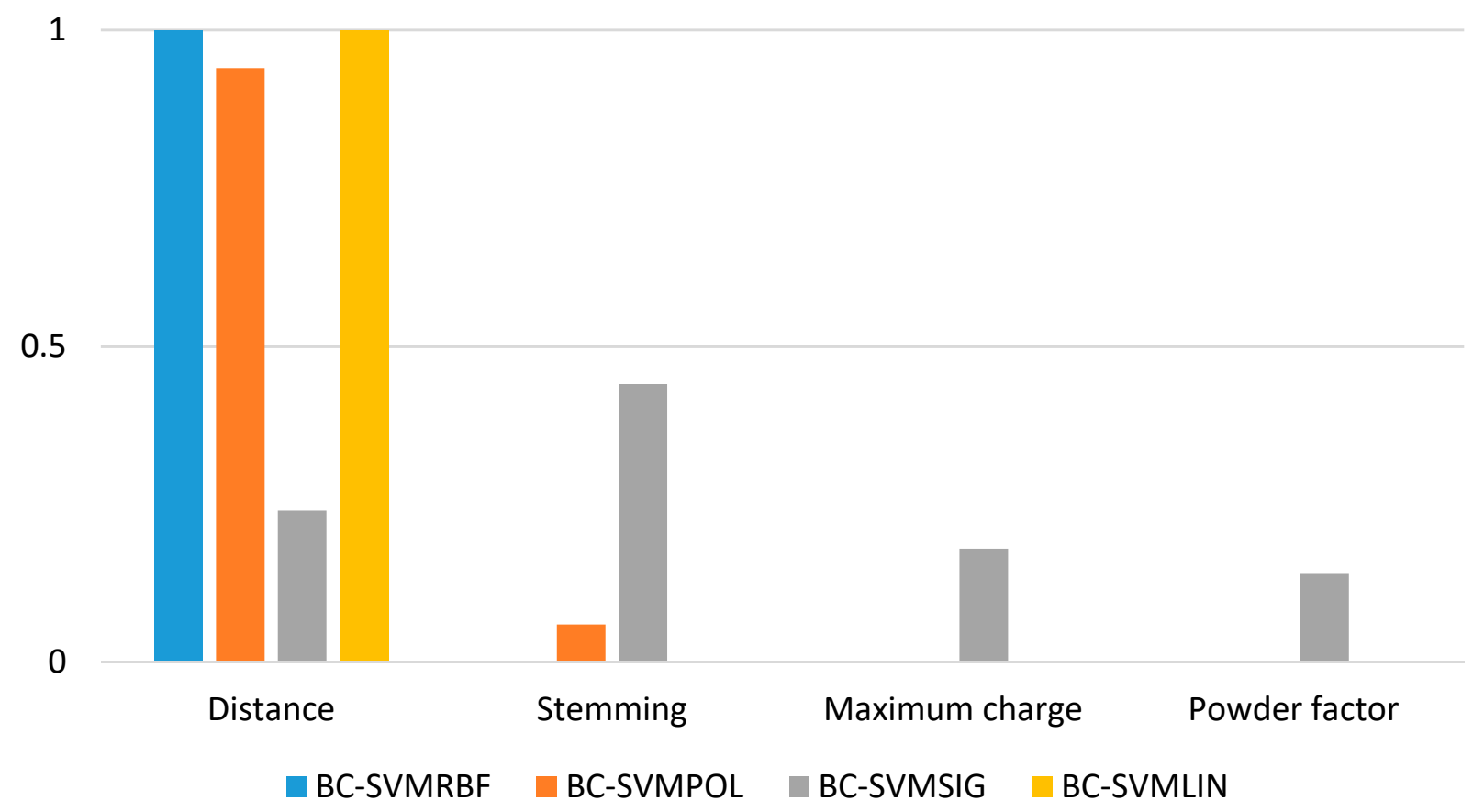

Figure 9. Input variable importance for the analysis of PPV.

\section{Discussion}

This study aimed to assess the feasibility of using a hybrid approach that combines a boosted-CHAID technique and SVM technique with different Kernels to predict the PPV induced by quarry blasting. The applied models were analyzed regarding accuracy, error, gain performance, and input variables' importance. The models' evaluation showed that the BC-SVMRBF model achieved the best performance, which shows the efficiency of hybridizing boosted-CHAID and SVM with RBF Kernel to predict the PPV. Alternatively, the BC-SVMSIG had the weakest performance in terms of accuracy, error, and gain, which showed that this hybridization approach is not suitable for predicting the PPV.

The finding of the present study in terms of better performance of RBF over other kernel types is in line with those of studies in other disciplines, which pointed out that the SVM model with RBF kernel has the greatest forecast capability (e.g., [91]).

Several properties of the RBF kernel may lead to its better performance over other kernel types. These properties included its stationarity and smoothness. Besides, the RBF kernel is isotropic. Here, stationary implies that the RBF is invariant to translation. RBF's isometric property refers to the fact that in $\mathrm{RBF}$, the scaling by $\gamma$ gives a similar value in all directions.

To support the efficiency of the proposed approaches, we applied two ANN models with two different structures, including Multilayer Perceptron (MLP) and Radial Basis Function (RBF) to the same data. The training $R$ values of 0.858 and 0.849 were achieved for ANNMLP and ANNRBF models, respectively. The results of these ANN models showed that all SVM models except SVMSIG outperformed the ANN models while were hybridized with the Boosted-CHAID method.

Compared to the previous studies on the same dataset, this study achieved a slightly lower accuracy than that of the study by Armaghani et al. [98]. In their study, Armaghani et al. applied ANN and ANFIS models to five inputs parameters to achieve an R of 
0.96, while in this study, the authors applied the hybrid models on four inputs to achieve acceptable training accuracy, especially for SVM with RBF Kernel (0.95). It can therefore be concluded that the proposed models in this study are considered as reliable and sufficiently accurate in predicting the PPV induced by blasting, while retaining the advantage of reduced complexity by employing fewer input parameters.

\section{Conclusions}

The aim of this research was to predict the PPV using a hybrid ML model enhanced with both boosted-CHAID and SVM techniques with different Kernels. The boostedCHAID model required only four out of a total of five input variables (distance from blast-face, stemming length, powder factor, and maximum charge per delay). Based on these input variables, different SVM kernels, i.e., SVMRBF, SVMPOL, SVMSIG, and SVMLIN, were designed to predict PPV values. Among these four SVM kernels, SVMRBF and SVMSIG were selected as the best and worst models, respectively, in predicting the PPV. The performance of the R and MAE index of the radial basis function kernel of SVM in training and testing phases respectively, confirm the high capability of this SVM kernel in predicting PPV values. With regards to the importance of PPV predictors, "distance" had the greatest importance, which is in line with the boosted-CHAID model results. All models also identified this input parameter as an influential predictor, which implies the importance of this predictor for PPV forecasting. The results of model importance are in line with the published intelligence and empirical studies in the area of PPV prediction.

This investigation intends to emphasize that this study's modeling method can be utilized in other disciplines to add a different problem-solving perspective. The performance of the SVM models is extensively impacted by the choice of the right values for " $\gamma$ " and " $d$ ". In the present study, we employed the grid-search technique for determining the optimal value for " $\gamma$ " and " $d$ ". Hence, the performance of the SVM models can be improved if the process of choosing " $\gamma$ " and " $d$ " is conducted by novel optimization techniques. Therefore, future studies on the employment of SVMs for PPV prediction should concentrate on adopting innovative soft computing optimization techniques to optimize values of kernel parameters.

While the present study selected the RBF kernel as the best kernel, it should be mentioned that the proper kernel function is problem specific. Thus, it can be an interesting topic for future studies to determine the practical process for picking appropriate kernel functions and their corresponding parameters' values consistent with the given problem.

Future investigations aiming at utilizing the SVM models may apply single and hybrid forms with various kernels in other environmental issues of blasting. It may also be of interest to apply the model to a wider database and enhance the model's prediction accuracy.

Author Contributions: Formal analysis, J.Z. and D.J.A.; Conceptualization, D.J.A. and S.A.F.; Supervision, P.G.A. and A.S.M.; Writing—review \& editing, D.J.A., S.A.F., A.S.M., P.C.R., C.M. and P.G.A. All authors have read and agreed to the published version of the manuscript.

Funding: Supported by the Science and Technology Research Program of Chongqing Municipal Education Commission (Grant NO. KJQN201804305, KJQN201904307).

Conflicts of Interest: The authors declare no conflict of interest. 


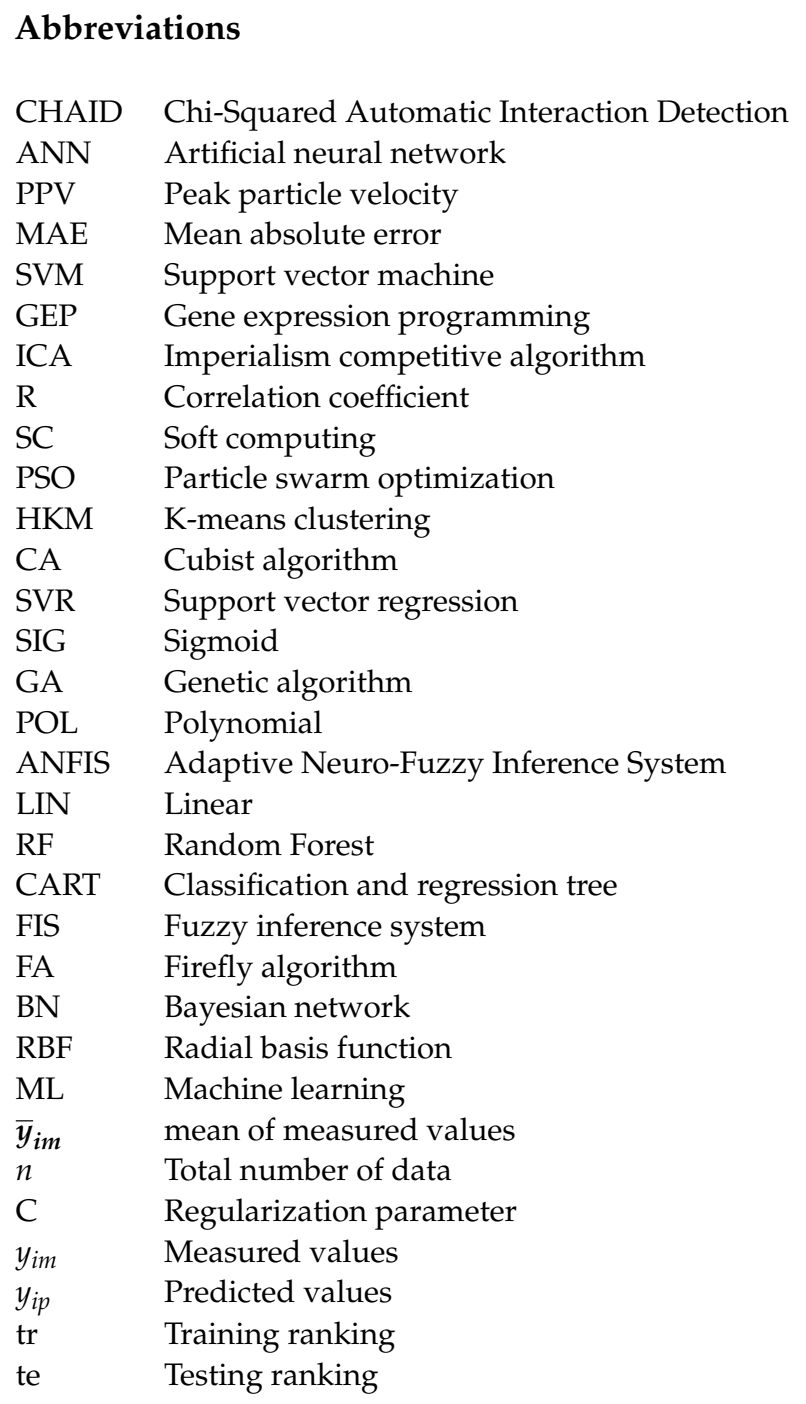

\section{References}

1. Armaghani, D.J.; Hajihassani, M.; Mohamad, E.T.; Marto, A.; Noorani, S.A. Blasting-induced flyrock and ground vibration prediction through an expert artificial neural network based on particle swarm optimization. Arab. J. Geosci. 2014, 7, 5383-5396. [CrossRef]

2. Hajihassani, M.; Jahed Armaghani, D.; Monjezi, M.; Mohamad, E.T.; Marto, A. Blast-induced air and ground vibration prediction: A particle swarm optimization-based artificial neural network approach. Environ. Earth Sci. 2015, 74, 2799-2817. [CrossRef]

3. Murlidhar, B.R.; Kumar, D.; Jahed Armaghani, D.; Mohamad, E.T.; Roy, B.; Pham, B.T. A Novel Intelligent ELM-BBO Technique for Predicting Distance of Mine Blasting-Induced Flyrock. Nat. Resour. Res. 2020, 29, 4103-4120. [CrossRef]

4. Han, H.; Armaghani, D.J.; Tarinejad, R.; Zhou, J.; Tahir, M.M. Random Forest and Bayesian Network Techniques for Probabilistic Prediction of Flyrock Induced by Blasting in Quarry Sites. Nat. Resour. Res. 2020, 29, 655-667. [CrossRef]

5. Huang, J.; Koopialipoor, M.; Armaghani, D.J. A combination of fuzzy Delphi method and hybrid ANN-based systems to forecast ground vibration resulting from blasting. Sci. Rep. 2020, 10, 1-21. [CrossRef]

6. Mahdiyar, A.; Jahed Armaghani, D.; Koopialipoor, M.; Hedayat, A.; Abdullah, A.; Yahya, K. Practical Risk Assessment of Ground Vibrations Resulting from Blasting, Using Gene Expression Programming and Monte Carlo Simulation Techniques. Appl. Sci. 2020, 10, 472. [CrossRef]

7. Hasanipanah, M.; Amnieh, H.B. A fuzzy rule-based approach to address uncertainty in risk assessment and prediction of blast-induced Flyrock in a quarry. Nat. Resour. Res. 2020. [CrossRef]

8. Bui, X.-N.; Choi, Y.; Atrushkevich, V.; Nguyen, H.; Tran, Q.-H.; Long, N.Q.; Hoang, H.-T. Prediction of blast-induced ground vibration intensity in open-pit mines using unmanned aerial vehicle and a novel intelligence system. Nat. Resour. Res. 2020, 29, 771-790. [CrossRef]

9. Nguyen, H.; Bui, X.-N. Predicting blast-induced air overpressure: A robust artificial intelligence system based on artificial neural networks and random forest. Nat. Resour. Res. 2019, 28, 893-907. [CrossRef] 
10. Murlidhar, B.R.; Bejarbaneh, B.Y.; Armaghani, D.J.; Mohammed, A.S.; Mohamad, E.T. Application of Tree-Based Predictive Models to Forecast Air Overpressure Induced by Mine Blasting. Nat. Resour. Res. 2020, 30, 1865-1887. [CrossRef]

11. Monjezi, M.; Hasanipanah, M.; Khandelwal, M. Evaluation and prediction of blast-induced ground vibration at Shur River Dam, Iran, by artificial neural network. Neural Comput. Appl. 2013, 22, 1637-1643. [CrossRef]

12. Khandelwal, M.; Monjezi, M. Prediction of backbreak in open-pit blasting operations using the machine learning method. Rock Mech. Rock Eng. 2013, 46, 389-396. [CrossRef]

13. Manoj, K.; Monjezi, M. Prediction of flyrock in open pit blasting operation using machine learning method. Int. J. Min. Sci. Technol. 2013, 23, 313-316. [CrossRef]

14. Tonnizam Mohamad, E.; Jahed Armaghani, D.; Hasanipanah, M.; Murlidhar, B.R.; Alel, M.N.A. Estimation of air-overpressure produced by blasting operation through a neuro-genetic technique. Environ. Earth Sci. 2016, 75, 1-15. [CrossRef]

15. Khandelwal, M.; Singh, T.N. Evaluation of blast-induced ground vibration predictors. Soil. Dyn. Earthq. Eng. 2007, 27, 116-125. [CrossRef]

16. Zhou, J.; Asteris, P.G.; Armaghani, D.J.; Pham, B.T. Prediction of ground vibration induced by blasting operations through the use of the Bayesian Network and random forest models. Soil Dyn. Earthq. Eng. 2020, 139, 106390. [CrossRef]

17. Hajihassani, M.; Jahed Armaghani, D.; Marto, A.; Tonnizam Mohamad, E. Ground vibration prediction in quarry blasting through an artificial neural network optimized by imperialist competitive algorithm. Bull. Eng. Geol. Environ. 2014, 74, 873-886. [CrossRef]

18. Khandelwal, M.; Singh, T.N. Prediction of blast-induced ground vibration using artificial neural network. Int. J. Rock Mech. Min. Sci. 2009, 46, 1214-1222. [CrossRef]

19. Monjezi, M.; Ghafurikalajahi, M.; Bahrami, A. Prediction of blast-induced ground vibration using artificial neural networks. Tunn. Undergr. Space Technol. 2011, 26, 46-50. [CrossRef]

20. Standard, I. Criteria for safety and design of structures subjected to under ground blast. ISI. IS-6922, 1973.

21. United States Bureau of Mines; Siskind, D. Structure Response and Damage Produced by Ground Vibration from Surface Mine Blasting; Department of the Interior, Bureau of Mines: New York, NY, USA, 1980.

22. Zhou, J.; Li, C.; Koopialipoor, M.; Jahed Armaghani, D.; Thai Pham, B. Development of a new methodology for estimating the amount of PPV in surface mines based on prediction and probabilistic models (GEP-MC). Int. J. Min. Reclam. Environ. 2020, 35, 48-68. [CrossRef]

23. Wiss, J.F.; Linehan, P.W. Control of Vibration and Blast Noise from Surface Coal Mining. Open File Report (Final) 1 July 1975-28 February 1978; Wiss, Janney, Elstner and Associates, Inc.: Northbrook, IL, USA, 1978; Volume 2.

24. Khandelwal, M.; Singh, T.N. Prediction of blast induced ground vibrations and frequency in opencast mine: A neural network approach. J. Sound Vib. 2006, 289, 711-725. [CrossRef]

25. Duvall, W.I.; Fogelson, D.E. Review of Criteria for Estimating Damage to Residences from Blasting Vibrations; US Department of the Interior, Bureau of Mines: Washington, DC, USA, 1962.

26. Ghosh, A.; Daemen, J.J.K. A simple new blast vibration predictor (based on wave propagation laws). In Proceedings of the 24th US Symposium on Rock Mechanics (USRMS), College Station, TX, USA, 20 June 1983; American Rock Mechanics Association: Alexandria, VA, USA, 1983.

27. Roy, P.P. Putting ground vibration predictors into practice. Colliery Guard. 1993, 241, 63-67.

28. Rahimi, I.; Gandomi, A.H.; Chen, F. Analysis and Prediction of COVID-19 using SIR, SEIR, and Machine Learning Models: Australia, Italy, and UK Cases. Information 2021, 12, 109. [CrossRef]

29. Asteris, P.G.; Douvika, M.G.; Karamani, C.A.; Skentou, A.D.; Chlichlia, K.; Cavaleri, L.; Daras, T.; Armaghani, D.J.; Zaoutis, T.E. A novel heuristic algorithm for the modeling and risk assessment of the covid-19 pandemic phenomenon. Comput. Model. Eng. Sci. 2020, 124, 1-14. [CrossRef]

30. Aghaabbasi, M.; Shekari, Z.A.; Shah, M.Z.; Olakunle, O.; Armaghani, D.J.; Moeinaddini, M. Predicting the use frequency of ride-sourcing by off-campus university students through random forest and Bayesian network techniques. Transp. Res. Part A Policy Pract. 2020, 136, 262-281. [CrossRef]

31. Dehghanbanadaki, A.; Khari, M.; Amiri, S.T.; Armaghani, D.J. Estimation of ultimate bearing capacity of driven piles in c- $\varphi$ soil using MLP-GWO and ANFIS-GWO models: A comparative study. Soft Comput. 2020, 25, 4103-4119. [CrossRef]

32. Zhou, J.; Koopialipoor, M.; Murlidhar, B.R.; Fatemi, S.A.; Tahir, M.M.; Armaghani, D.J.; Li, C. Use of Intelligent Methods to Design Effective Pattern Parameters of Mine Blasting to Minimize Flyrock Distance. Nat. Resour. Res. 2019, 1-15. [CrossRef]

33. Zhou, J.; Shi, X.; Li, X. Utilizing gradient boosted machine for the prediction of damage to residential structures owing to blasting vibrations of open pit mining. J. Vib. Control 2016, 22, 3986-3997. [CrossRef]

34. Zhou, J.; Li, E.; Yang, S.; Wang, M.; Shi, X.; Yao, S.; Mitri, H.S. Slope stability prediction for circular mode failure using gradient boosting machine approach based on an updated database of case histories. Saf. Sci. 2019, 118, 505-518. [CrossRef]

35. Armaghani, D.J.; Asteris, P.G. A comparative study of ANN and ANFIS models for the prediction of cement-based mortar materials compressive strength. Neural Comput. Appl. 2020, 1-32. [CrossRef]

36. Apostolopoulou, M.; Asteris, P.G.; Armaghani, D.J.; Douvika, M.G.; Lourenço, P.B.; Cavaleri, L.; Bakolas, A.; Moropoulou, A. Mapping and holistic design of natural hydraulic lime mortars. Cem. Concr. Res. 2020, 136, 106167. [CrossRef]

37. Zeng, J.; Asteris, P.G.; Mamou, A.P.; Mohammed, A.S.; Golias, E.A.; Armaghani, D.J.; Faizi, K.; Hasanipanah, M. The Effectiveness of Ensemble-Neural Network Techniques to Predict Peak Uplift Resistance of Buried Pipes in Reinforced Sand. Appl. Sci. 2021, 11, 908. [CrossRef] 
38. Jahed Armaghani, D.; Asteris, P.G.; Askarian, B.; Hasanipanah, M.; Tarinejad, R.; Huynh, V. Van Examining Hybrid and Single SVM Models with Different Kernels to Predict Rock Brittleness. Sustainability 2020, 12, 2229. [CrossRef]

39. Duan, J.; Asteris, P.G.; Nguyen, H.; Bui, X.-N.; Moayedi, H. A novel artificial intelligence technique to predict compressive strength of recycled aggregate concrete using ICA-XGBoost model. Eng. Comput. 2020, 1-18. [CrossRef]

40. Lu, S.; Koopialipoor, M.; Asteris, P.G.; Bahri, M.; Armaghani, D.J. A Novel Feature Selection Approach Based on Tree Models for Evaluating the Punching Shear Capacity of Steel Fiber-Reinforced Concrete Flat Slabs. Materials 2020, 13, 3902. [CrossRef] [PubMed]

41. Asteris, P.G.; Apostolopoulou, M.; Armaghani, D.J.; Cavaleri, L.; Chountalas, A.T.; Guney, D.; Hajihassani, M.; Hasanipanah, M.; Khandelwal, M.; Karamani, C.; et al. On the metaheuristic models for the prediction of cement-metakaolin mortars compressive strength. Metaheuristic Comput. Appl. 2020, 1, 63-99.

42. Armaghani, D.J.; Asteris, P.G.; Fatemi, S.A.; Hasanipanah, M.; Tarinejad, R.; Rashid, A.S.A.; Huynh, V. Van On the Use of Neuro-Swarm System to Forecast the Pile Settlement. Appl. Sci. 2020, 10, 1904. [CrossRef]

43. Zhao, J.; Nguyen, H.; Nguyen-Thoi, T.; Asteris, P.G.; Zhou, J. Improved Levenberg-Marquardt backpropagation neural network by particle swarm and whale optimization algorithms to predict the deflection of RC beams. Eng. Comput. 2021, 1-23. [CrossRef]

44. Apostolopoulou, M.; Armaghani, D.J.; Bakolas, A.; Douvika, M.G.; Moropoulou, A.; Asteris, P.G. Compressive strength of natural hydraulic lime mortars using soft computing techniques. Procedia Struct. Integr. 2019, 17, 914-923. [CrossRef]

45. Sarir, P.; Chen, J.; Asteris, P.G.; Armaghani, D.J.; Tahir, M.M. Developing GEP tree-based, neuro-swarm, and whale optimization models for evaluation of bearing capacity of concrete-filled steel tube columns. Eng. Comput. 2019, 1-19. [CrossRef]

46. Huang, J.; Kumar, G.S.; Sun, Y. Evaluation of workability and mechanical properties of asphalt binder and mixture modified with waste toner. Constr. Build. Mater. 2021, 276, 122230. [CrossRef]

47. Kardani, N.; Bardhan, A.; Kim, D.; Samui, P.; Zhou, A. Modelling the energy performance of residential buildings using advanced computational frameworks based on RVM, GMDH, ANFIS-BBO and ANFIS-IPSO. J. Build. Eng. 2021, 35, 102105. [CrossRef]

48. Khari, M.; Armaghani, D.J.; Dehghanbanadaki, A. Prediction of Lateral Deflection of Small-Scale Piles Using Hybrid PSO-ANN Model. Arab. J. Sci. Eng. 2019, 1-11. [CrossRef]

49. Momeni, E.; Yarivand, A.; Bagher Dowlatshahi, M.; Jahed Armaghani, D. An Efficient Optimal Neural Network Based on Gravitational Search Algorithm in Predicting the Deformation of Geogrid-Reinforced Soil Structures. Transp. Geotech. 2020, 26, 100446. [CrossRef]

50. Zhang, H.; Nguyen, H.; Bui, X.-N.; Pradhan, B.; Asteris, P.G.; Costache, R.; Aryal, J. A generalized artificial intelligence model for estimating the friction angle of clays in evaluating slope stability using a deep neural network and Harris Hawks optimization algorithm. Eng. Comput. 2021, 1-14. [CrossRef]

51. Apostolopoulour, M.; Douvika, M.G.; Kanellopoulos, I.N.; Moropoulou, A.; Asteris, P.G. Prediction of Compressive Strength of Mortars using Artificial Neural Networks. In Proceedings of the 1st International Conference TMM_CH, Transdisciplinary Multispectral Modelling and Cooperation for the Preservation of Cultural Heritage, Athens, Greece, 10-13 October 2018; pp. 10-13.

52. Psyllaki, P.; Stamatiou, K.; Iliadis, I.; Mourlas, A.; Asteris, P.; Vaxevanidis, N. Surface treatment of tool steels against galling failure. In Proceedings of the MATEC Web of Conferences, Warsaw, Poland, 5-7 October 2018; EDP Sciences: Les Ulis, France; Volume 188, p. 4024.

53. Kechagias, J.; Tsiolikas, A.; Asteris, P.; Vaxevanidis, N. Optimizing ANN performance using DOE: Application on turning of a titanium alloy. In Proceedings of the MATEC Web of Conferences, Taichung, Taiwan, 28 October-1 November 2017; EDP Sciences: Les Ulis, France; Volume 178, p. 1017.

54. Huang, L.; Asteris, P.G.; Koopialipoor, M.; Armaghani, D.J.; Tahir, M.M. Invasive Weed Optimization Technique-Based ANN to the Prediction of Rock Tensile Strength. Appl. Sci. 2019, 9, 5372. [CrossRef]

55. Huang, J.; Asteris, P.G.; Pasha, S.M.K.; Mohammed, A.S.; Hasanipanah, M. A new auto-tuning model for predicting the rock fragmentation: A cat swarm optimization algorithm. Eng. Comput. 2020, 1-12. [CrossRef]

56. Ly, H.B.; Pham, B.T.; Le, L.M.; Le, T.T.; Le, V.M.; Asteris, P.G. Estimation of axial load-carrying capacity of concrete-filled steel tubes using surrogate models. Neural Comput. Appl. 2020, 33, 3437-3458. [CrossRef]

57. Asteris, P.G.; Cavaleri, L.; Ly, H.-B.; Pham, B.T. Surrogate models for the compressive strength mapping of cement mortar materials. Soft Comput. 2021, 25, 6347-6372. [CrossRef]

58. Huang, J.; Wang, Q.-A. Influence of crumb rubber particle sizes on rutting, low temperature cracking, fracture, and bond strength properties of asphalt binder. Mater. Struct. 2021, 54, 1-15. [CrossRef]

59. Huang, J.; Duan, T.; Zhang, Y.; Liu, J.; Zhang, J.; Lei, Y. Predicting the permeability of pervious concrete based on the beetle antennae search algorithm and random forest model. Adv. Civ. Eng. 2020, 2020. [CrossRef]

60. Huang, J.; Sun, Y.; Zhang, J. Reduction of computational error by optimizing SVR kernel coefficients to simulate concrete compressive strength through the use of a human learning optimization algorithm. Eng. Comput. 2021, 1-18. [CrossRef]

61. Huang, J.; Zhang, J.; Ren, J.; Chen, H. Anti-rutting performance of the damping asphalt mixtures (DAMs) made with a high content of asphalt rubber (AR). Constr. Build. Mater. 2021, 271, 121878. [CrossRef]

62. Yang, H.; Liu, J.; Liu, B. Investigation on the cracking character of jointed rock mass beneath TBM disc cutter. Rock Mech. Rock Eng. 2018, 51, 1263-1277. [CrossRef]

63. Yang, H.Q.; Li, Z.; Jie, T.Q.; Zhang, Z.Q. Effects of joints on the cutting behavior of disc cutter running on the jointed rock mass. Tunn. Undergr. Space Technol. 2018, 81, 112-120. [CrossRef] 
64. Yang, H.; Wang, Z.; Song, K. A new hybrid grey wolf optimizer-feature weighted-multiple kernel-support vector regression technique to predict TBM performance. Eng. Comput. 2020, 1-17. [CrossRef]

65. Liu, B.; Yang, H.; Karekal, S. Effect of Water Content on Argillization of Mudstone During the Tunnelling process. Rock Mech. Rock Eng. 2019, 53, 799-813. [CrossRef]

66. Zhou, J.; Li, X.; Mitri, H.S. Comparative performance of six supervised learning methods for the development of models of hard rock pillar stability prediction. Nat. Hazards 2015, 79, 291-316. [CrossRef]

67. Zhou, J.; Li, X.; Mitri, H.S. Evaluation method of rockburst: State-of-the-art literature review. Tunn. Undergr. Space Technol. 2018, 81, 632-659. [CrossRef]

68. Gavriilaki, E.; Asteris, P.G.; Touloumenidou, T.; Koravou, E.-E.; Koutra, M.; Papayanni, P.G.; Karali, V.; Papalexandri, A.; Varelas, C.; Chatzopoulou, F.; et al. Genetic justification of severe COVID-19 using a rigorous algorithm. Clin. Immunol. 2021, 9, 108726. [CrossRef]

69. Singh, T.N.; Singh, V. An intelligent approach to prediction and control ground vibration in mines. Geotech. Geol. Eng. 2005, 23, 249-262. [CrossRef]

70. Fişne, A.; Kuzu, C.; Hüdaverdi, T. Prediction of environmental impacts of quarry blasting operation using fuzzy logic. Environ. Monit. Assess. 2011, 174, 461-470. [CrossRef]

71. Saadat, M.; Khandelwal, M.; Monjezi, M. An ANN-based approach to predict blast-induced ground vibration of Gol-E-Gohar iron ore mine, Iran. J. Rock Mech. Geotech. Eng. 2014, 6, 67-76. [CrossRef]

72. Shirani Faradonbeh, R.; Jahed Armaghani, D.; Abd Majid, M.Z.; MD Tahir, M.; Ramesh Murlidhar, B.; Monjezi, M.; Wong, H.M. Prediction of ground vibration due to quarry blasting based on gene expression programming: A new model for peak particle velocity prediction. Int. J. Environ. Sci. Technol. 2016, 13, 1453-1464. [CrossRef]

73. Nguyen, H.; Bui, X.-N.; Tran, Q.-H.; Mai, N.-L. A new soft computing model for estimating and controlling blast-produced ground vibration based on hierarchical K-means clustering and cubist algorithms. Appl. Soft Comput. 2019, 77, 376-386. [CrossRef]

74. Nguyen, H.; Choi, Y.; Bui, X.-N.; Nguyen-Thoi, T. Predicting Blast-Induced Ground Vibration in Open-Pit Mines Using Vibration Sensors and Support Vector Regression-Based Optimization Algorithms. Sensors 2020, 20, 132. [CrossRef]

75. Zhang, H.; Zhou, J.; Armaghani, D.J.; Tahir, M.M.; Pham, B.T.; Huynh, V.V. A Combination of Feature Selection and Random Forest Techniques to Solve a Problem Related to Blast-Induced Ground Vibration. Appl. Sci. 2020, 10, 869. [CrossRef]

76. Iphar, M.; Yavuz, M.; Ak, H. Prediction of ground vibrations resulting from the blasting operations in an open-pit mine by adaptive neuro-fuzzy inference system. Environ. Geol. 2008, 56, 97-107. [CrossRef]

77. Mohamed, M.T. Performance of fuzzy logic and artificial neural network in prediction of ground and air vibrations. Int. J. Rock Mech. Min. Sci. 2011, 48, 845. [CrossRef]

78. Khandelwal, M.; Kumar, D.L.; Yellishetty, M. Application of soft computing to predict blast-induced ground vibration. Eng. Comput. 2011, 27, 117-125. [CrossRef]

79. Mohamadnejad, M.; Gholami, R.; Ataei, M. Comparison of intelligence science techniques and empirical methods for prediction of blasting vibrations. Tunn. Undergr. Space Technol. 2012, 28, 238-244. [CrossRef]

80. Mohamad, E.T.; Noorani, S.A.; Armaghani, D.J.; Saad, R. Simulation of blasting induced ground vibration by using artificial neural network. Electron. J. Geotech. Eng. 2012, 17, 2571-2584.

81. Ghasemi, E.; Ataei, M.; Hashemolhosseini, H. Development of a fuzzy model for predicting ground vibration caused by rock blasting in surface mining. J. Vib. Control 2013, 19, 755-770. [CrossRef]

82. Dindarloo, S.R. Peak particle velocity prediction using support vector machines: A surface blasting case study. J. South. Afr. Inst. Min. Metall. 2015, 115, 637-643. [CrossRef]

83. Hasanipanah, M.; Monjezi, M.; Shahnazar, A.; Armaghani, D.J.; Farazmand, A. Feasibility of indirect determination of blast induced ground vibration based on support vector machine. Measurement 2015, 75, 289-297. [CrossRef]

84. Armaghani, D.J.; Momeni, E.; Abad, S.V.A.N.K.; Khandelwal, M. Feasibility of ANFIS model for prediction of ground vibrations resulting from quarry blasting. Environ. Earth Sci. 2015, 74, 2845-2860. [CrossRef]

85. Ghoraba, S.; Monjezi, M.; Talebi, N.; Armaghani, D.J.; Moghaddam, M.R. Estimation of ground vibration produced by blasting operations through intelligent and empirical models. Environ. Earth Sci. 2016, 75, 1-9. [CrossRef]

86. Hasanipanah, M.; Faradonbeh, R.S.; Amnieh, H.B.; Armaghani, D.J.; Monjezi, M. Forecasting blast-induced ground vibration developing a CART model. Eng. Comput. 2017, 33, 307-316. [CrossRef]

87. Shahnazar, A.; Nikafshan Rad, H.; Hasanipanah, M.; Tahir, M.M.; Jahed Armaghani, D.; Ghoroqi, M. A new developed approach for the prediction of ground vibration using a hybrid PSO-optimized ANFIS-based model. Environ. Earth Sci. 2017, 76, 1-17. [CrossRef]

88. Armaghani, D.J.; Hasanipanah, M.; Amnieh, H.B.; Mohamad, E.T. Feasibility of ICA in approximating ground vibration resulting from mine blasting. Neural Comput. Appl. 2018, 29, 457-465. [CrossRef]

89. Kass, G.V. An exploratory technique for investigating large quantities of categorical data. J. R. Stat. Soc. Ser. C (Appl. Stat.) 1980, 29, 119-127. [CrossRef]

90. Freund, Y.; Schapire, R.E. Experiments with a new boosting algorithm. In Proceedings of the Thirteenth International Conference on Machine Learning, Bary, Italy, 3-6 July 1996; Volume 96, pp. 148-156.

91. Tien Bui, D.; Pradhan, B.; Lofman, O.; Revhaug, I. Landslide susceptibility assessment in vietnam using support vector machines, decision tree, and Naive Bayes Models. Math. Probl. Eng. 2012, 2012. [CrossRef] 
92. Jebur, M.N.; Pradhan, B.; Tehrany, M.S. Optimization of landslide conditioning factors using very high-resolution airborne laser scanning (LiDAR) data at catchment scale. Remote Sens. Environ. 2014, 152, 150-165. [CrossRef]

93. Marjanović, M.; Kovačević, M.; Bajat, B.; Voženílek, V. Landslide susceptibility assessment using SVM machine learning algorithm. Eng. Geol. 2011, 123, 225-234. [CrossRef]

94. Song, S.; Zhan, Z.; Long, Z.; Zhang, J.; Yao, L. Comparative study of SVM methods combined with voxel selection for object category classification on fMRI data. PLoS ONE 2011, 6, e17191. [CrossRef]

95. Tehrany, M.S.; Pradhan, B.; Jebur, M.N. Flood susceptibility mapping using a novel ensemble weights-of-evidence and support vector machine models in GIS. J. Hydrol. 2014, 512, 332-343. [CrossRef]

96. Bhandari, S. Engineering Rock Blasting Operations; CRC Press/Balkema: Rotterdam, The Netherlands, 1997 ; p. 388.

97. Chen, W.; Hasanipanah, M.; Rad, H.N.; Armaghani, D.J.; Tahir, M.M. A new design of evolutionary hybrid optimization of SVR model in predicting the blast-induced ground vibration. Eng. Comput. 2019, 1-17. [CrossRef]

98. Jahed Armaghani, D.; Hajihassani, M.; Monjezi, M.; Mohamad, E.T.; Marto, A.; Moghaddam, M.R. Application of two intelligent systems in predicting environmental impacts of quarry blasting. Arab. J. Geosci. 2015, 8, 9647-9665. [CrossRef] 